\title{
Juniper Berry Oil
}

National Cancer Institute

\section{Source}

National Cancer Institute. Juniper Berry Oil. NCI Thesaurus. Code C72206.

The essential oil extracted from juniper berries. Juniper berry oil is used in aromatherapy and perfumery. 